\title{
Dependence of Bacillus stearothermophilus Spore Germination on Nutrient Depletion and Manganese
}

\author{
By HON YEUNG CHEUNG, † LJUBIŠA VITKOVIĆ† AND \\ MICHAEL R. W. BROWN* \\ Microbiology Research Group, Department of Pharmacy, University of Aston in Birmingham, \\ Birmingham B4 7ET, U.K.
}

(Received 14 January 1982)

\begin{abstract}
Spores of Bacillus stearothermophilus NCTC 10003 germinated without delay in glucose/glutamate chemically defined medium at $60{ }^{\circ} \mathrm{C}$. The nature of the nutrient limitation inducing sporulation affected the ability of spores to germinate under the conditions studied. Spores produced after glucose depletion of the medium (carbon-depleted spores) germinated faster and to a greater extent than did spores produced after sulphate depletion of the medium (sulphurdepleted spores). Sub-lethal heat treatment $\left(80^{\circ} \mathrm{C}, 10 \mathrm{~min}\right)$ prior to germination enhanced dormancy. L-Alanine $\left(0.2 \mathrm{mg} \mathrm{ml}^{-1}\right)$ did not reverse this effect, nor did it enhance the germination of sulphur-depleted spores. The rate and extent of germination for both kinds of spores was proportional to the intrasporal manganese concentration. In contrast, extrasporal manganese exerted an inhibitory effect and it was not required for germination. We conclude that the nature of the nutrient depletion and the level of intrasporal manganese distinctly affect the extent and rate of spore germination.
\end{abstract}

\section{INTRODUCTION}

Conditions for bacterial spore germination have been reviewed by Gould (1969), and overt morphological and biochemical changes accompanying germination have been characterized (Levinson \& Hyatt, 1966; Dring \& Gould, 1971; Setlow \& Primus, 1975; Watabe \& Kondo, 1975; Scott et al., 1978). Since the discovery of the specific requirement for manganese in sporulation (Charney et al., 1951) and the manganese stimulatory effect on germination (Levinson \& Sevag, 1952), the role of divalent metal ions in the cell cycle of Bacillus species has been intensely studied. However, previous studies on the influence of manganese on germination did not distinguish the intrasporal $\mathrm{Mn}^{2+}$ from that in the germination media (Levinson \& Sevag, 1952; Gould, 1969). Recent experimental evidence has provided strong indications that mobilization of spore manganese plays a critical regulatory role in germination (Singh \& Setlow, 1978; 1979; Vasantha \& Freese, 1979). If this is true, then the level of intrasporal manganese may be more important in spore germination than that of extrasporal manganese added to germination media.

Furthermore, comparatively little is known concerning how nutrient depletion and other sporulation conditions affect germination. It has been reported that depletion of a particular nutrient by cells growing in a chemically defined medium results in spores of specific characteristics (Brown \& Hodges, 1974). Therefore, in order to explore the germination mechanism, the history of the spores under study should be carefully traced. Appropriate manipulation of the sporulation medium by nutrient depletion in combination with adjustment of divalent metal ion concentrations may yield spores of specified characteristics offering a clearer insight into spore germination.

† Present address: Laboratory of Molecular Biology, National Institute of Neurological and Communicative Disorders and Stroke, Bethesda, Maryland 20205, U.S.A. 
In this paper, we describe the effects of nutrient depletion during sporulation on germination of Bacillus stearothermophilus spores and how these effects vary with the intra- and extrasporal concentrations of manganese.

\section{METHODS}

Spore preparation. Bacillus stearothermophilus NCTC 10003 cells growing exponentially in $25 \mathrm{ml}$ of a chemically defined medium (CDM) were used as an inoculum after $6 \mathrm{~h}$ incubation at $60^{\circ} \mathrm{C}$. The CDM contained $17.6 \mathrm{mM}$ $\mathrm{Na}_{2} \mathrm{HPO}_{4}, 2.4 \mathrm{mM}$-L-glutamate, $7.3 \mathrm{mM}-\mathrm{KH}_{2} \mathrm{PO}_{4}, 7.5 \mathrm{~mm}$-D-glucose, $9.35 \mathrm{~mm}-\mathrm{NH}_{4} \mathrm{Cl}, 10 \mu \mathrm{M}-\mathrm{FeCl}_{3}, 10 \mu \mathrm{M}$ $\mathrm{MnCl}_{2}, 0.5 \mathrm{mM}-\mathrm{MgCl}_{2}, 0.1 \mathrm{mM}-\mathrm{CaCl}_{2}$ and $0.1 \mathrm{mM}-\mathrm{Na}_{2} \mathrm{SO}_{4}(\mathrm{pH} 7)$; this medium was found to support good growth of this strain (Cheung et al., 1982). The inoculum cells were washed twice with pre-warmed medium containing all nutrients in the sporulation medium except the nutrient intended to limit cell growth. They were then added to 500 $\mathrm{ml}$ chemically defined medium such that depletion of either the carbon source (glucose) or the sulphur source $\left(\mathrm{Na}_{2} \mathrm{SO}_{4}\right)$ limited exponential growth and led to spore formation. When preparing nutrient-depleted spores with different intrasporal manganese levels, the manganese concentration in the medium was varied as stated below, keeping all other nutrient concentrations constant. Spores were harvested by centrifugation after $60 \mathrm{~h}$ incubation at $60{ }^{\circ} \mathrm{C}$ with aeration at $800 \mathrm{ml} \mathrm{min}^{-1}$. They were then washed 10 times in cold sterile deionized distilled water, resuspended $\left(1-5 \times 10^{8}\right.$ spores $\left.\mathrm{ml}^{-1}\right)$ in phosphate-buffered saline $(5 \mathrm{mM}, \mathrm{pH} 7 \cdot 2)$ and stored at $4{ }^{\circ} \mathrm{C}$. In each batch, $1-4 \%$ of spores appeared non-refractile under the phase-contrast microscope after more than 2 months storage.

Assay of divalent metal ions. Spore contents of $\mathrm{Mn}^{2+}, \mathrm{Mg}^{2+}, \mathrm{Ca}^{2+}$ and $\mathrm{Fe}^{2+}$ were measured using a Unicam SP90 atomic absorption spectrophotometer. Spores were washed twice with deionized distilled water, dried in a desiccator and dissolved in $1 \mathrm{M}-\mathrm{HCl}$ by autoclaving for $1 \mathrm{~h}$. The samples were then diluted in water and assayed in duplicate, taking three readings for each measurement. Contaminating levels of $\mathrm{Mn}^{2+}$ in the medium were always less than $10^{-7} \mathrm{M}$ as determined by a Perkin-Elmer 560 flameless atomic absorption spectrophotometer.

Determination of dipicolinic acid. The dipicolinic acid content of spores was measured polarographically in acidified samples using method 1 of Porter et al. (1967).

Heat-shock treatment. Spores washed twice and resuspended in appropriate amounts of sterile deionized distilled water were heated for $10 \mathrm{~min}$ at $80^{\circ} \mathrm{C}$. After heat-shock, the spores were immediately transferred to prewarmed CDM for an assessment of germination. Survival of the heat-shocked spores was measured by plating serially diluted spore suspensions in triplicate on $0.5 \%(\mathrm{w} / \mathrm{v})$ glucose $/ 1 \%(\mathrm{w} / \mathrm{v})$ tryptone agar. Plates were incubated at $60^{\circ} \mathrm{C}$ for $24 \mathrm{~h}$ and colonies were then counted.

Spore germination. Nutrient-depleted spores suspended in phosphate-buffered saline ( $5 \mathrm{mM}, \mathrm{pH} 7 \cdot 2)$ and kept at $4{ }^{\circ} \mathrm{C}$ were resuspended in pre-warmed $\mathrm{CDM}$ which induced germination. Germination was measured either by monitoring the decrease in turbidity at $470 \mathrm{~nm}\left(A_{470}\right)$ of appropriately diluted spore suspensions and/or by counting the number of phase-dark spores in a haemocytometer counting chamber (Hawksley \& Son) under a phase-contrast microscope. The initial $A_{470}$ was always between 0.8 and 1.0 . Spores were induced to germinate with or without prior heat-shock by shaking the suspension at $60^{\circ} \mathrm{C}$. The $A_{470}$ was measured at specified time intervals and a standard curve for the conversion of low percentage transmittance to true turbidity was used (Lawrence \& Maier, 1977). Confirmation of germination was obtained by observing changes in refractility using a phase-contrast microscope. In the method of phase-dark spore counting, a sample of the germinating spore suspension was immediately mixed with an equal quantity of $5 \mathrm{M}-\mathrm{HCl}$ in a test tube in order to prevent further germination. A few drops of the mixture were later placed on counting chambers and counted. Germination rates were estimated by measuring the initial slope of the germination curves.

\section{RESULTS}

\section{Spore composition and properties}

We examined the spore contents of divalent cations and dipicolinic acid in relation to the initial $\mathrm{Mn}^{2+}$ concentration in the medium with sulphur or carbon source depletion limiting growth and causing sporulation. Spore contents of $\mathrm{Ca}^{2+}, \mathrm{Fe}^{2+}, \mathrm{Mg}^{2+}$ and dipicolinic acid appeared to vary slightly and randomly with respect to the $\mathrm{Mn}^{2+}$ concentration in the medium (Table 1). The intrasporal concentration of $\mathrm{Mn}^{2+}$ was proportional to the initial concentration of $\mathrm{Mn}^{2+}$ in the medium for both carbon- and sulphur-depleted spores. Both kinds of spores were, on average, equally capable of giving rise to colonies after $24 \mathrm{~h}$ incubation on plates. Approximately $66-90 \%$ of spores were viable.

\section{Effect of nutrient depletion and heat shock on germination}

Spores of $B$. stearothermophilus were induced to germinate by resuspending them in CDM at $60{ }^{\circ} \mathrm{C}$. When approximately $25 \%$ of the phase-bright spores had become phase-dark, the $A_{470}$ 
Table 1. Dipicolinic acid $(D P A)$ and divalent metal ion contents of $B$. stearothermophilus spores harvested from media containing various concentrations of $\mathrm{Mn}^{2+}$

DPA and metal ion contents are expressed as $\mu \mathrm{g}$ per $10^{7}$ spores.

\begin{tabular}{|c|c|c|c|c|c|c|c|c|c|c|}
\hline \multirow{2}{*}{$\begin{array}{c}\text { Medium } \\
\mathrm{Mn}^{2+} \\
\text { concn } \\
(\mu \mathrm{M})\end{array}$} & \multicolumn{5}{|c|}{ Sulphur-depleted spores } & \multicolumn{5}{|c|}{ Carbon-depleted spores } \\
\hline & DPA & $\mathrm{Ca}^{2+}$ & $\mathrm{Fe}^{2+}$ & $\mathrm{Mg}^{2+}$ & $\mathrm{Mn}^{2+}$ & DPA & $\mathrm{Ca}^{2+}$ & $\mathrm{Fe}^{2+}$ & $\mathrm{Mg}^{2+}$ & $\mathrm{Mn}^{2+}$ \\
\hline $2 \cdot 1$ & $1 \cdot 29$ & $0 \cdot 32$ & 0.091 & $0 \cdot 038$ & 0.035 & $1 \cdot 15$ & $0 \cdot 32$ & 0.055 & 0.025 & 0.027 \\
\hline $5 \cdot 0$ & 1.59 & 0.44 & $0 \cdot 084$ & $0 \cdot 056$ & $0 \cdot 039$ & - & - & - & - & - \\
\hline $10 \cdot 0$ & 1.89 & 0.57 & $0 \cdot 165$ & 0.053 & 0.067 & 1.53 & 0.49 & $0 \cdot 251$ & 0.052 & 0.067 \\
\hline $62 \cdot 5$ & $2 \cdot 06$ & 0.64 & $0 \cdot 169$ & $0 \cdot 061$ & $0 \cdot 147$ & $1 \cdot 57$ & 0.48 & $0 \cdot 179$ & 0.032 & 0.083 \\
\hline $100 \cdot 0$ & 1.74 & 0.59 & $0 \cdot 107$ & 0.052 & $0 \cdot 158$ & $1 \cdot 59$ & 0.48 & 0.223 & 0.048 & $0 \cdot 186$ \\
\hline
\end{tabular}

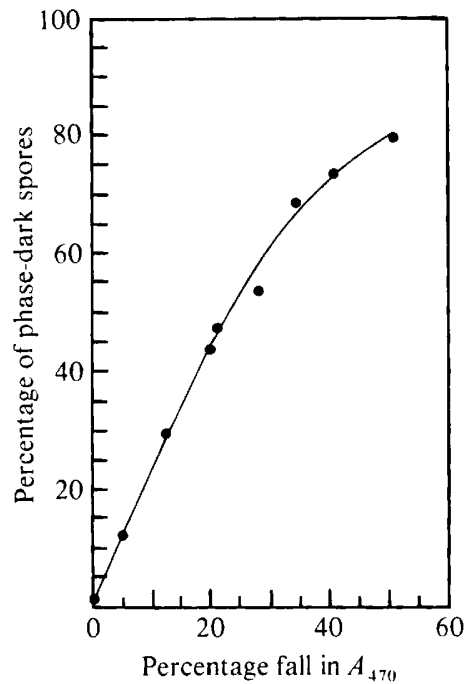

Fig. 1

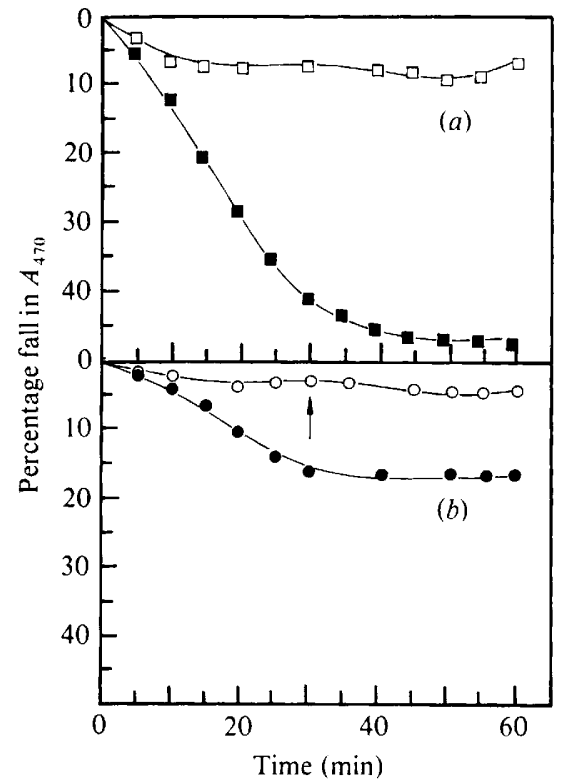

Fig. 2

Fig. 1. Correlation between germination and decrease in $A_{470}$. Carbon-depleted spores containing $186 \mathrm{ng}$ $\mathrm{Mn}^{2-}$ per $10^{7}$ spores were induced to germinate as described in Methods. Every 5 min a sample of the spore suspension was removed. Its $\boldsymbol{A}_{470}$ was measured and expressed as a percentage of the initial $\boldsymbol{A}_{470}$. The phase-dark spores in this sample were then counted and their number expressed as a percentage of the total number of spores present.

Fig. 2. Germination of nutrient-depleted spores with or without heat shock. Carbon-depleted (a) and sulphur-depleted $(b)$ spores were induced to germinate with $(\square, \bigcirc)$ or without $(\square, \bigcirc)$ heat shock as described in Methods. The extent of germination was assessed at $5 \mathrm{~min}$ intervals by measuring the decrease in $A_{470}$ of the suspension. The arrow in $(b)$ indicates the time when L-alanine $\left(0 \cdot 2 \mathrm{mg} \mathrm{ml}^{-1}\right)$ was added to the germination medium. Carbon-depleted spores contained $186 \mathrm{ng} \mathrm{Mn^{2+ }}$ per $10^{7}$ spores and

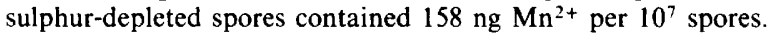

had decreased by $10 \%$. This relationship departed from linearity when the decrease in $A_{470}$ was more than $20 \%$ (Fig. 1). All spores examined germinated without the apparent delay commonly observed with spores of Bacillus cereus T (Gould, 1969). Although the exact time courses varied slightly from experiment to experiment, the extent and rate of germination was reproducible and was always higher for carbon-depleted spores than for sulphur-depleted spores (Figs 2, 3 and 4). These observations suggest that sulphur-depleted spores were more dormant, although colony counts indicated that approximately similar percentages of spores were viable after long periods of incubation. 


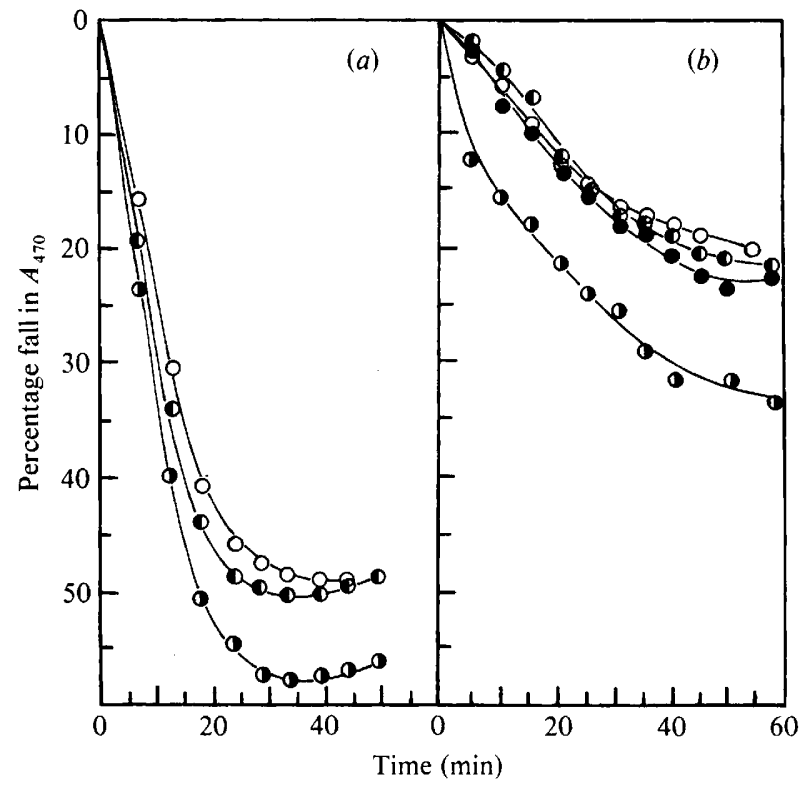

Fig. 3. Effect of extrasporal $\mathrm{Mn}^{2+}$ on the germination of nutrient-depleted spores. Carbon-depleted (a) and sulphur-depleted $(b)$ spores were induced to germinate in CDM containing $2 \cdot 1(\mathcal{O}), 10(\mathrm{D}), 62 \cdot 5$ (O) and $100(\mathrm{O}) \mu \mathrm{M}-\mathrm{Mn}^{2+}$, as described in Methods. Germination was assessed by measuring the fall in $A_{470}$. Intrasporal $\mathrm{Mn}^{2+}$ levels were the same as in Fig. 2.

Spores of some Bacillus species are activated to germinate by heat shock (Gould, 1969; Srivastava \& Fitz-James, 1981). Figure 2 depicts the germination of heat-shocked carbon- and sulphur-depleted spores compared with controls. In both cases spores became more dormant after the heat-shock treatment. The majority of control spores germinated in 60 min while the heat-shocked spores remained dormant for more than $6 \mathrm{~h}$ and then the $A_{470}$ increased rather than decreased. The increase in $A_{470}$ was associated with outgrowth of some spores followed by the first cell division (as observed microscopically). Plating on glucose/tryptone agar indicated that only $13 \%$ of both kinds of spores were inactivated by heat-shock treatment before germination. In contrast, $62 \%$ of sulphur- and $53 \%$ of carbon-depleted spores were inactivated by incubation at $100{ }^{\circ} \mathrm{C}$ for $30 \mathrm{~min}$ (data not shown). Therefore, sub-lethal heat treatment of this strain was not only ineffective in activating germination but actually enhanced dormancy. In CDM, spores were most probably triggered to germinate by glucose. In order to assess whether an additional triggering compound would accelerate germination, $\mathrm{L}$-alanine $\left(0.2 \mathrm{mg} \mathrm{ml}^{-1}\right)$ was added to the medium (Fig. $2 b$, arrow). In repeated experiments $A_{470}$ remained unchanged indicating that L-alanine was unable to trigger germination of sulphur-depleted spores. Carbondepleted spores were not treated with $\mathrm{L}$-alanine since they germinated extensively without it. We conclude from these data that CDM permits germination of $B$. stearothermophilus spores and that the nature of the nutrient limitation inducing sporulation affects their ability to germinate.

\section{Effect of extra- and intrasporal manganese on spore germination}

We wanted to investigate whether the germination kinetics were influenced by extra- and intrasporal manganese levels. Nutrient-depleted spores containing different amounts of manganese were suspended in media containing increasing concentrations of $\mathrm{Mn}^{2+}$ and were examined for germination. Spores germinated similarly in the absence and presence of $2 \cdot 1 \mu \mathrm{M}-\mathrm{Mn}^{2+}$. The total numbers of germinated sulphur-depleted spores at $60 \mathrm{~min}$, as well as their germination rates, decreased slightly as the $\mathrm{Mn}^{2+}$ concentration in the germination medium was increased (Fig. $3 b$ ). The germination of carbon-depleted spores was similarly affected by extrasporal 


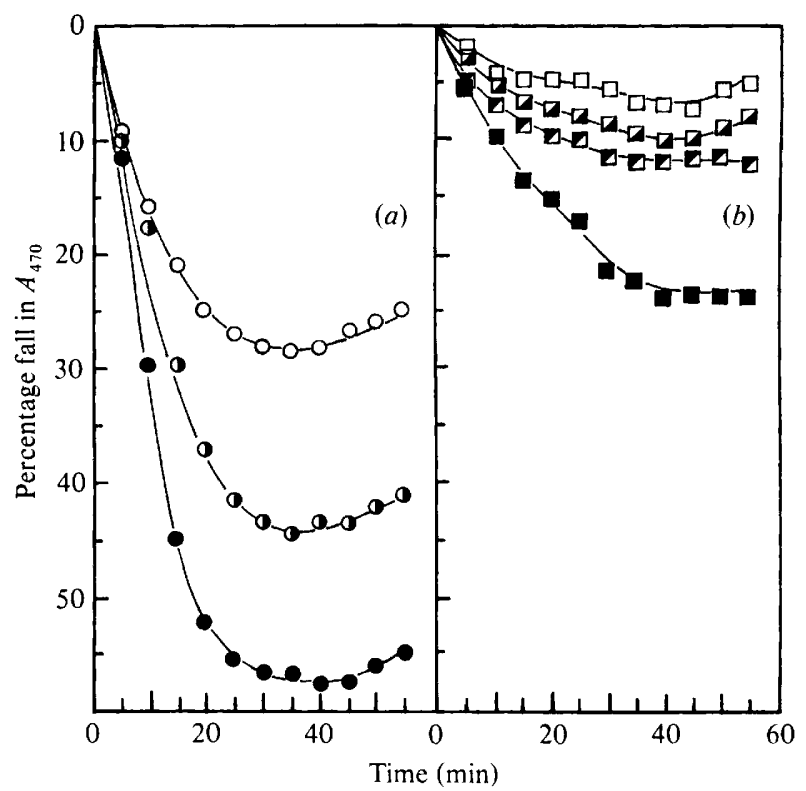

Fig. 4. Germination time course of nutrient-depleted spores as a function of intrasporal manganese

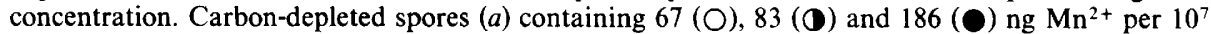
spores and sulphur-depleted spores $(b)$ containing $35(\square), 67(\square), 147(\square)$ and $158(\square) n g$ Mn $^{2+}$ per $10^{7}$ spores were induced to germinate as described in Methods. Germination was assessed by measuring the decrease in $A_{470}$ of samples withdrawn at $5 \mathrm{~min}$ intervals. Chemically defined germination medium contained $10 \mu \mathrm{M}-\mathrm{Mn}^{2+}$.

manganese except that it proceeded faster and to a greater extent than that of sulphur-depleted spores (Fig. $3 a$ ). Germination of spores containing lower levels of manganese was less inhibited by the $\mathrm{Mn}^{2+}$ concentration in the germination medium when compared to spores with high manganese content (data not shown). Intrasporal manganese concentration appeared to have a larger impact on the rate and extent of germination than did manganese present in the germination medium (Fig. 4). The rate and extent of germination of both sulphur- and carbon-depleted spores was proportional to the intrasporal manganese concentration. Approximately two to three times as many carbon-depleted spores germinated in $60 \mathrm{~min}$ as compared to sulphurdepleted spores containing comparable amounts of $\mathrm{Mn}^{2+}$. The germination of carbon-depleted spores showed a greater dependence on intrasporal $\mathrm{Mn}^{2+}$ than did germination of sulphurdepleted spores (Fig. 4).

\section{DISCUSSION}

The time course of germination of $B$. stearothermophilus spores varied with the nature of the nutrient limiting vegetative growth and inducing sporulation in the chemically defined medium. Sulphur-depleted spores appeared to be more dormant; they germinated more slowly and to a lesser extent than carbon-depleted spores. These observations are consistent with the findings of Morris \& Hansen (1981) who have recently reported that thiol groups in the spore coat of $B$. cereus became increasingly exposed during germination and that their covalent modification inhibited outgrowth. Similarly, an increase in the thiol content of coat proteins extracted from both isolated coats and whole cells accompanies augmentation of germination by heat shock in B. cereus (Srivastava \& Fitz-James, 1981). The structure of the spore coat proteins determines their hydrolysis rates as well as the interaction with germination-triggering compounds. Both processes contribute to the overall germination rate. Sulphate in the sporulation medium was the only sulphur source for the synthesis of cysteine and other sulphur-containing compounds. Polypeptides rich in half-cysteine cause the spore coat to be a high sulphur-containing keratin- 
like structure (Aronson \& Fitz-James, 1976) and this may be modified in sulphur-depleted spores.

Spores of Bacillus species require different triggering compounds and may need heat shock to initiate germination (Foerster \& Foster, 1966; Gould, 1969). Some spores can be triggered to germinate by glucose (Vary, 1978), others by L-alanine (Scott et al., 1978) and L-proline (Rossignol \& Vary, 1979). Our results indicate that spores of $B$. stearothermophilus NCTC 10003 require glucose for germination. Exposure of $B$. stearothermophilus spores to $80^{\circ} \mathrm{C}$ for $10 \mathrm{~min}$ failed to activate their germination system and enhanced dormancy. This effect could not be reversed by L-alanine or D-glucose. Heat-induced spore dormancy in two other B. stearothermophilus strains has also been observed, when spores were heated in water at 80,90 and $100^{\circ} \mathrm{C}$ (Finley \& Fields, 1962). The reasons for this phenomenon remain unknown.

Manganese levels in carbon- and sulphur-depleted spores of $B$. stearothermophilus were directly proportional to the initial concentrations of this ion in the sporulation medium. Similar results were reported for B. megaterium (Slepecky \& Foster, 1959; Levinson \& Hyatt, 1966) and B. fastidiosus (Aoki \& Slepecky, 1973). Both the rate and extent of germination increased as the manganese concentration in the spores increased. This effect was observed regardless of the nutrient depletion, although it was less pronounced in sulphur-depleted spores probably due to their high dormancy. Free $\mathrm{Mn}^{2+}$ serves as a preferred cofactor for 3-phosphoglycerate mutase (Oh \& Freese, 1976), the enzyme which provides energy for germination (Singh \& Setlow, 1979). It is possible that spores with higher intrasporal manganese concentrations have higher amounts of free $\mathrm{Mn}^{2+}$ released from bound forms at the earliest stage of germination; this would increase energy production and accelerate germination. However, our results do not exclude other possibly unidentified changes which may have altered the extent and rate of germination. In contrast to intrasporal manganese, exogenous manganese exerted a smaller and inhibitory effect on germination. Manganese in the medium also inhibits germination of spores of $B$. megaterium (Levinson \& Hyatt, 1966) and B. fastidiosus (Aoki \& Slepecky, 1973). The effect was smaller because exogenous $\mathrm{Mn}^{2+}$ may reach the spore protoplast after intrasporal ions have already exerted their influence on germination. During the early stages of germination, transport systems are neither activated nor synthesized (Scott et al., 1978). The effect was inhibitory possibly due to manganese uptake utilizing some of the metabolic energy (Eisenstadt et al., 1973; Silver et al., 1975; Stahl, 1978) needed for germination or because of a manganese inhibition of macromolecular synthesis as occurs in vegetative cells (Eisenstadt et al., 1973). However, further experimental evidence is necessary to investigate these possibilities.

We thank E. R. Allen for critical reading of the manuscript.

\section{REFERENCES}

AOKI, H. \& SlePeCKY, R. A. (1973). Inducement of heat-shock requirement for germination and production of increased heat resistance in Bacillus fastidiosus spores by manganese ions. Journal of Bacteriology 114, 137-143.

Aronson, A. I. \& Fitz-James, P. C. (1976). Structure and morphogenesis of the bacterial spore coat. Bacteriological Reviews 40, 360-402.

Brown, M. R. W. \& Hodges, N. A. (1974). Growth and sporulation characteristics of Bacillus megaterium under different conditions of nutrient limitation. Journal of Pharmacy and Pharmacology 26, 217227.

Charney, J., Fisher, W. P. \& Hegarty, C. P. (1951). Manganese as an essential element for sporulation in the genus Bacillus. Journal of Bacteriology 62, 145148.

Cheung, H. Y., Vitković, L. \& Brown, M. R. W. (1982). Toxic effect of manganese on growth and sporulation of Bacillus stearothermophilus. Journal of General Microbiology 128, 2395-2402.

DrING, G. J. \& GoULD, G. W. (1971). Sequence of events during rapid germination of spores of Bacillus cereus. Journal of General Microbiology 65, 101-104.

Eisenstadt, E., Fisher, S., Der, C. L. \& Silver, S. (1973). Manganese transport in Bacillus subtilis W23 during growth and sporulation. Journal of Bacteriology 113, 1363-1372.

FinLEY, N. \& Fields, M. L. (1962). Heat activation and heat-induced dormancy of Bacillus stearothermophilus spores. Applied Microbiology 10, 231-236.

FOERSTER, H. F. \& Foster, J. W. (1966). Response of Bacillus spores to combinations of germinative compounds. Journal of Bacteriology 91, 1168-1177.

Gould, G. W. (1969). Germination. In The Bacterial Spore, pp. 397-444. Edited by G. W. Gould \& A. Hurst, New York: Academic Press.

LAWRenCE, J. V. \& MaIER, S. (1977), Correction for the inherent error in optical density readings. $A p$ plied and Environmental Microbiology 33, 482-484.

LEVINSON, H. S. \& HyatT, M. T. (1966). Sequence of events during Bacillus megaterium spore germination. Journal of Bacteriology 91, 1811-1818.

LeVInson, H. S. \& SevaG, M. G. (1952). Stimulation of 
germination and respiration of the spores of Bacillus megaterium by manganese and monovalent anions. Journal of General Physiology 36, 617-629.

MORRIS, L. S. \& HANSEN, J. N. (1981). Inhibition of Bacillus cereus spore outgrowth by covalent modification of a sulfhydryl group by nitrosothiol and iodoacetate. Journal of Bacteriology 148, 465-471.

OH, Y. K. \& FreESE, E. (1976). Manganese requirement of phosphoglycerate phosphomutase and its consequences for growth and sporulation of Bacillus subtilis. Journal of Bacteriology 127, 739-746.

Porter, G. S., Brown, M. W. \& Brown, M. R. W. (1967). Polarographic determination of dipicolinic acid in the presence of bacterial spores and vegetative cells. Biochemical Journal 102, 19C.

Rossignol, D. P. \& VARY, J. C. (1979). L-Proline site for triggering Bacillus megaterium spore germination. Biochemical and Biophysical Research Communications 89, 547-551.

SCOtT, I, R., Gordon, S. A. B., Stewart, G. S. A. B., Koncewicz, M. A., Ellar, D. J. \& Crofts-Lighty, A. (1978). Sequence of biochemical events during germination of Bacillus megaterium spores. In Spores $V I I$, pp. 95-103. Edited by G. Chambliss \& J. C. Vary. Washington, D.C.: American Society for Microbiology.

Setlow, P. \& Primus, G. (1975). Protein degradation and amino acid metabolism during germination of Bacillus megaterium spores. In Spores VI, pp. 451457. Edited by P. Gerhardt, R. N. Costilow \& H. L. Sadoff. Washington, D.C.: American Society for Microbiology.

Silver, S., Toth, K. \& SCRIBNer, H. (1975). Facilitated transport of calcium by cells and subcellular mem- branes of Bacillus subtilis and Escherichia coli. Journal of Bacteriology 122, 880-885.

Singh, R. P. \& Setlow, P. (1978). Phosphoglycerate mutase in developing forespores of Bacillus megaterium may be regulated by the intrasporal level of free manganese ion. Biochemical and Biophysical Research Communications 82, 1-5.

Singh, R. P. \& Setlow, P. (1979). Regulation of phosphoglycerate phosphomutase in developing forespores and dormant and germinated spores of Bacillus megaterium by level of free manganese ions. Journal of Bacteriology 139, 889-898.

SLEPECKY, R. \& FosteR, J. W. (1959). Alterations in metal content of spores of Bacillus megaterium and the effect on some properties. Journal of Bacteriology 78, 117-123.

Srivastava, O. P. \& Fitz-James, P. C. (1981). Alteration by heat activation of enzymes localized in spore coats of Bacillus cereus. Canadian Journal of Microbiology 27, 408-416.

STAHL, S. (1978). Calcium uptake and survival of Bacillus stearothermophilus. Archives of Microbiology 119 , 17-24.

VARY, J. C. (1978). Glucose-initiated germination in Bacillus megaterium spores. In Spores VII, pp. 104108. Edited by G. Chambliss \& J. C. Vary. Washington, D.C.: American Society for Microbiology.

VASANTHA, N. \& Freese, E. (1979). The role of manganese in growth and sporulation of Bacillus subtilis. Journal of General Microbiology 112, 329-336.

WATABE, K. \& KondO, M. (1975). Changes of ultrastructure in spore coat of Bacillus thiaminolyticus during germination and outgrowth. Japanese Journal of Microbiology 19, 187-192. 